\title{
The effect of calcium on fibrinolysis in vitro
}

\author{
SALLY BRUCE 1
}

From the Haematology Department, St. George's Hospital, London

SYNOPSIS The influence of calcium on fibrinolysis in vitro has been studied. In the absence of
inhibitors, fibrinolytic activity is enhanced by calcium. In whole blood the inhibitory effect $\vec{O}$
calcium on fibrinolysis can be explained by its effect on the inhibitors present. Anti-activator
dependent on the presence of calcium for its formation, although calcium has no further influence
on its action. Antiplasmin activity is enhanced by the presence of calcium.

There have been many conflicting reports on the effect of calcium on the fibrinolytic system. Fearnley and Tweed (1953) first observed that ionic calcium caused some inhibition of diluted plasma clot lysis. This was later confirmed by Sherry, Lindemeyer, Fletcher, and Alkjaersig (1959), and Thomas (1958) reported the inhibition of streptokinase-induced clot lysis by calcium. Ratnoff (1952), however, noted an accelerating effect of calcium on the euglobulin lysis time, and this was confirmed by Kowalski, Kopec, and Niewiaroswki (1959).

Explanations of the inhibitory effect of calcium on plasma clot lysis were given by Bidwell (1953), who suggested that the type of fibrin influences the rate of fibrinolysis, and by Bickford and Sokolow (1961), who suggested that the urea-insoluble fibrin formed in the presence of calcium is less susceptible to fibrinolysis than the urea-soluble form. Medart (1958) proposed that calcium disturbs the equilibrium between two forms of fibrinogen, the one susceptible, the other inhibitory, to fibrinolysis. None of these workers took into account the conflicting results reported by Ratnoff (1952) in the euglobulin lysis time.

Ratnoff concluded that the acceleration of euglobulin clot lysis was due to the effect of calcium on the activation of plasminogen, and not on the action of plasmin. Although this fits in with the subsequent findings of Kowalski, Latallo, and Niewiarowski (1956) that the activity of plasmin is not influenced by calcium, Ratnoff could not demonstrate its effect on the activation of plasminogen by streptokinase or chloroform.

In the light of these reports it was thought that the influence of calcium on the fibrinolytic system 'Present address: Children's Medical Research Foundation, Royal Alexandra Hospital for Children, Camperdown, New South Wales, Australia.

Received for publication 18 October 1963. should be more fully investigated, in order \&o discover whether calcium accelerates or inhibits fibrinolysis, and, if the latter, whether it acts direc on plasmin or indirectly through the inhibitors. The inhibitory components of the fibrinolytic systeren considered in this paper are the combined effect the antiplasmins (Norman, 1960) and the antit activator effect described by Flute (1960). In plasna the inactive precursor plasminogen is acted upon blood activator to form the fibrinolytic enzynie plasmin. This activation of plasminogen to plasmin is inhibited by anti-activator, which is formed rapidfy on incubation of blood in glass (Flute, 1960). The proteolytic action of plasmin on fibrin is inhibited by the antiplasmins which are present in circulatiog blood (Norman, 1960). The effect of calcium on the fibrinolytic system as a whole is measured in plasmg. To separate the enzymes and their inhibitors use is made of the euglobulin precipitation method. The euglobulin fraction prepared at $4^{\circ} \mathrm{C}$. immediate after collection of blood is used as a source of activator, plasminogen, and plasmin, free from inhibitors. The effect of calcium on anti-activator is tested in the euglobulin fraction prepared from incubated plasma or serum. This fraction wit contain anti-activator but no antiplasmins. The rofe of calcium in the formation of anti-activator nis studied by comparing euglobulin fractions of serunm incubated both in the presence and absence of calcium. The combined influence of anti-activator and antiplasmin is measured in incubated serum. In this way the effect of calcium on the components of the fibrinolytic system has been studied.

\section{REAGENTS}

Human venous blood was used as a source of most of t迎 components of the fibrinolytic system. 
DECALCIFYING AGENTS These are (1) $10 \%$ dipotassium ethylene diamine tetra-acetate (E.D.T.A.) $(0 \cdot 1 \mathrm{ml} . / 10 \mathrm{ml}$. blood); (2) $3.8 \%$ trisodium citrate $(1 \mathrm{ml} . / 10 \mathrm{ml}$. blood); and (3) $0.1 \mathrm{M}$ ammonium oxalate $(1 \mathrm{ml} . / 10 \mathrm{ml}$. blood).

The E.D.T.A. interfered to some extent with the subsequent clotting procedures, and, as citrate was found to be suitable for the removal of calcium in these experiments, this was used in the majority of the tests.

FIBRINOGEN Solution of bovine fibrinogen (bovine plasma fraction I, Armour Pharmaceutical Co.) containing $0.5 \mathrm{~g}$. in $100 \mathrm{ml}$. buffer.

THROMBIN Solution of bovine thrombin (Thrombin Reagent, Leo Pharmaceutical Products) containing 50 N.J.H. units $/ \mathrm{ml}$. saline. This has been found to be free from significant contamination by components of the fibrinolytic system.

STREPTOKINASE Streptokinase-streptodornase Varidase (Lederle Laboratories).

BUFFERS Veronal buffer, $p \mathrm{H} 7 \cdot 4$, ionic strength $0 \cdot 154$, was prepared from the following formula: sodium diethyl barbiturate, 11.745 g., sodium chloride $14.67 \mathrm{~g}$., $0 \cdot 1 \mathrm{~N}$ hydrochloric acid $430 \mathrm{ml}$., distilled water to 2 litres.


sodium chloride $9 \mathrm{~g}$., sodium borate $1 \mathrm{~g}$., distilled water to 1 litre.

\section{METHODS}

SEPARATION OF THE ENZYMES FROM THEIR INHIBITORS Inhibitor-free euglobulin fraction was prepared by the following method. Venous blood was collected into a plastic syringe which had been cooled to $4^{\circ} \mathrm{C}$. and placed in a precooled plastic tube containing anticoagulant and immediately centrifuged at $1,710 \mathrm{~g}$ (3,250 r.p.m.) for 10 minutes at $4^{\circ} \mathrm{C}$. The platelet-poor plasma was transferred to 18 times its volume of ice-cold distilled water and the $p \mathrm{H}$ adjusted to $5 \cdot 3$ by the addition of $1 \%$ acetic acid (usually one-fifth of the plasma volume). This was allowed to stand at $4^{\circ} \mathrm{C}$. for 30 minutes, then centrifuged at $1,710 \mathrm{~g}\left(3,250\right.$ r.p.m.) for 10 minutes at $4^{\circ} \mathrm{C}$. and the supernatant discarded. The resulting euglobulin precipitate was free from significant antiplasmin activity; meticulous observance of the cold handling technique and use of plastic apparatus prevented the formation of antiactivator.

Antiplasmin-free euglobulin fraction was prepared from plasma or serum which had been incubated in a glass container at $37^{\circ} \mathrm{C}$. for 30 minutes to allow formation of anti-activator. Once formed, this is precipitated with the euglobulin fraction (Flute, 1960).

MEASUREMENT OF FIBRINOLYTIC ACTIVITY The fibrin plate (Astrup and Müllertz, 1952) was prepared using bovine fibrinogen $(0.5 \mathrm{~g}$. Armour plasma fraction $1 / 100 \mathrm{ml}$. buffer) and thrombin, modified by the incorporation of $1 \mathrm{ml}$. $0.01 \mathrm{M} \mathrm{CaCl}_{2}$ or $0.12 \mathrm{M} \mathrm{NaCl}$ in the plate. The results are expressed as the product of two diameters of the area of lysis in square millimetres. In this paper all results quoted are the means of three readings.
The heated fibrin plate (Lassen, 1953) was prepared using bovine fibrinogen and thrombin, again modified by the inclusion of calcium or sodium chloride in the plate.

The euglobulin lysis time was determined as follows:The euglobulin precipitate derived from $0.5 \mathrm{ml}$. plasma is dissolved in $0.5 \mathrm{ml}$. buffer. To $0.4 \mathrm{ml}$. of this solution $0.5 \mathrm{ml}$. $0.01 \mathrm{M} \mathrm{CaCl}_{2}, 0.025 \mathrm{M} \mathrm{CaCl}_{2}$ or $0.12 \mathrm{M} \mathrm{NaCl}$ is added, and the mixture clotted with $0.1 \mathrm{ml}$. thrombin. The time taken for complete dissolution of the clot at $37^{\circ} \mathrm{C}$. is called the euglobulin lysis time.

\section{RESULTS}

EFFECT OF CALCIUM ON FIBRINOLYSIS AS MEASURED IN PLASMA Citrated platelet-poor plasma was activated by adding streptokinase, 100 units $/ \mathrm{ml}$. plasma, and aliquots were applied immediately to unheated fibrin plates, containing calcium or sodium chloride. As shown in Table I, there is significantly less lysis in the presence of calcium. It must be borne in mind

\section{TABLE I}

LYSIS PRODUCED BY STREPTOKINASE-ACTIVATED PLASMA ON FIBRIN PLATES IN PRESENCE AND ABSENCE OF CALCIUM

\begin{tabular}{llrrrrrr} 
& Test Plasma & 1 & 2 & 3 & 4 & 5 & 6 \\
\hline Standard plates & Without calcium & $662^{1}$ & 252 & 142 & 20 & 664 & 613 \\
& Calcium present & 352 & 107 & 48 & trace & 482 & 559 \\
Heated plates & Without calcium & 49 & 46 & 42 & 30 & 78 & 36 \\
& Calcium present & 25 & 23 & 29 & 20 & 69 & 9
\end{tabular}

${ }^{1}$ These figures represent the areas of lysis in square millimetres, and are the means of three readings.

that these results were influenced by activation by streptokinase of the plasminogen contaminating commercial fibrinogen, and also by any contaminant inhibitors which may be present.

Streptokinase-activated plasma was also tested on heated fibrin plates. Although the results do not indicate such significant differences (Table I) as those on the unheated plates, there is consistently less lysis when calcium is present. Heating destroys the contaminating plasminogen and inhibitors in the plate, and these results therefore depend on the activity of the plasmin formed by activation by streptokinase of the plasminogen in the plasma sample: they are also influenced by the inhibitors in the plasma.

These results indicate that calcium inhibits fibrinolysis in plasma.

EFFECT OF CALCIUM ON FIBRINOLYSIS AS MEASURED IN INHIBITOR-FREE EUGLOBULIN FRACTION Euglobulin lysis times were carried out on blood taken from stressed and unstressed individuals, in all cases preparing the euglobulin fraction at $4^{\circ} \mathrm{C}$. As seen in Table II lysis times are much shorter when calcium 
TABLE II

EFFECT OF CALCIUM ON FIBRINOLYSIS IN THE ABSENCE OF INHIBITORS $^{1}$

\begin{tabular}{cllcc}
$\begin{array}{c}\text { Plasma } \\
\text { Sample }\end{array}$ & Anticoagulant & Buffer & $\begin{array}{l}\text { Without } \\
\text { Calcium }\end{array}$ & $\begin{array}{l}\text { Calcium } \\
\text { Present }\end{array}$ \\
\hline 1 & Oxalate & Veronal & 425 & 205 \\
& Citrate & Veronal & 350 & 180 \\
& Oxalate & Borate & 550 & 170 \\
2 & Citrate & Borate & 440 & 160 \\
3 & Citrate & Borate & 320 & 120 \\
4 & Citrate & Veronal & 101 & 96 \\
5 & Citrate & Veronal & 135 & 123 \\
6 & Citrate & Veronal & 360 & 290 \\
7 & Citrate & Veronal & 255 & 180 \\
8 Post- & Citrate & Veronal & 240 & 190 \\
Citrate & Veronal & 16 & 13
\end{tabular}

${ }^{1}$ The euglobulin lysis times are expressed in minutes in the presence and absence of calcium using inhibitor-free euglobulin fraction,

is present. This is independent of the anticoagulant or buffer used. The euglobulin lysis time under these conditions is a measure of the activity of activator and plasmin; it is not influenced by anti-activator or anti-plasmin activity. From these results it appears that fibrinolysis, in the absence of inhibitors, is accelerated by calcium. It is not possible to tell whether calcium acts on the activator or on plasmin.

Inhibitor-free euglobulin fraction was applied to unheated fibrin plates. Lysis was greater in the plates containing calcium (Table III). These results also indicate that calcium enhances fibrinolysis in the absence of inhibitors.

\section{TABLE III}

EFFECT OF CALCIUM ON FIBRINOLYSIS IN THE ABSENCE OF INHIBITORS $^{1}$

\begin{tabular}{lrrrrr} 
Test Sample & 1 & 2 & 3 & 4 & 5 \\
\hline Without calcium & 90 & 40 & 340 & 110 & 60 \\
Calcium present & 330 & 120 & 370 & 160 & 90
\end{tabular}

${ }^{1}$ Lysis was produced by inhibitor-free euglobulin fraction on unheated fibrin plates, in the presence and absence of calcium. Areas of lysis in square millimetres representing the mean of three readings.

Fibrinolysis, as measured in the inhibitor-free euglobulin fraction, is enhanced by calcium. It was thought that the inhibitory action of calcium on fibrinolysis as measured in plasma might be explained by its effect on the inhibitors.

INFLUENCE OF CALCIUMON PREFORMED ANTI-ACTIVATOR Inhibitor-free euglobulin fraction and antiplasminfree euglobulin fraction were prepared from the same citrated plasma samples. Euglobulin lysis times were carried out on both fractions, with and without the addition of calcium, and the results are shown in Table IV. The longer lysis times recorded
TABLE IV

INFLUENCE OF CALCIUM ON PREFORMED ANTI-ACTIVATOR?

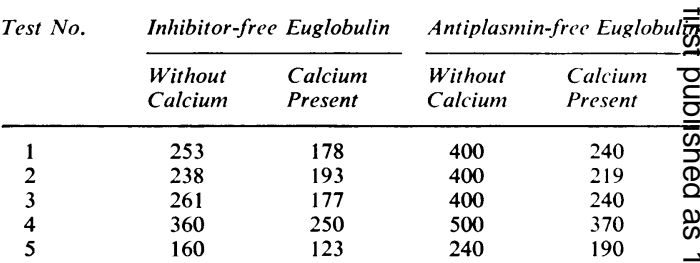

${ }^{1}$ Euglobulin lysis times ( $\mathrm{min}$.) in the presence and absence of calcium using inhibitor-free euglobulin fraction and antiplasmin-free euglobulin fraction. Antiplasmin-free euglobulin fraction is prepared frofy citrated plasma after incubation to allow development of antiactivator

using the antiplasmin-free euglobulin fraction indicate the presence of anti-activator in this fraction. Calcium accelerates the rate of lysis in bots fractions to a comparable degree, indicating thate the inhibition caused by anti-activator is noi enhanced by calcium.

Inhibitor-free euglobulin fraction was prepare from citrated plasma. Antiplasmin-free euglobulim fraction was prepared from incubated serumg E.D.T.A. having been added to the serum aftês incubation $(0.01 \mathrm{ml} .10 \%$ E.D.T.A. per ml. serumb Euglobulin lysis times were then set up, using $0.4 \mathrm{~m}$ inhibitor-free euglobulin fraction and varyin amounts of antiplasmin-free euglobulin fraction in clot of volume $1.1 \mathrm{ml}$. Calcium or sodium chloride was added before clotting with thrombin. As seen i Table V, the addition of antiplasmin-free euglobuli fraction prolongs the euglobulin lysis time, due to the presence of anti-activator. Calcium, howeve does not increase this inhibition. Thus anti-activator once formed, is not influenced by calcium, and the inhibitory action of calcium on whole blood lysis cannot be explained by its effect on anti-activator.

EFFECT OF CALCIUM ON DEVELOPMENT OF ANT ACTIVATOR in vitro There remains the effect of calcium on the formation of anti-activator, and Flute (1962) has suggested that calcium is inde necessary for its formation. Anti-activator is n $\overline{\overline{Q T}}$ identifiable as such in circulating blood, but $\oiint$ formed after incubation in contact with glas (Flute, 1960). In order to test the effect of calcium of its formation, $3 \mathrm{ml}$. platelet-poor E.D.T.A. plasma $(0.1 \mathrm{ml} .10 \%$ E.D.T.A. per $100 \mathrm{ml}$. plasma $)$ and 3 n. native plasma were clotted with $0.1 \mathrm{ml}$. thromb (500 N.I.H. units $/ \mathrm{ml}$.), incubated in glass for 30 minutes at $37^{\circ} \mathrm{C}$. The clots were then removed E.D.T.A. added to the serum containing none, an euglobulin precipitates prepared from each. Tre anti-activator activity of each of these fractions wa tested by adding varying amounts to $0.4 \mathrm{ng}$ inhibitor-free euglobulin fraction, and carryitrg 
TABLE V

INFLUENCE OF CALCIUM ON PREFORMED ANTI-ACTIVATOR ${ }^{1}$ Added Antiplasmin-free Euglobulin

$0 \quad 0.1 \mathrm{ml} .0 .2 \mathrm{ml} .0 .3 \mathrm{ml} .0 .4 \mathrm{ml} .0 .5 \mathrm{ml}$.

\begin{tabular}{lllllll}
\hline Without calcium & 135 & 154 & 225 & 255 & 345 & 345 \\
Calcium present & 125 & 149 & 195 & 225 & 285 & 285
\end{tabular}

${ }^{1}$ Euglobulin lysis times (min.) in the presence and absence of calcium, with the addition of increasing amounts of antiplasmin-free euglobulin fraction containing preformed anti-activator. Antiplasmin-free euglobulin fraction prepared from incubated serum and added to constant amounts of inhibitor-free euglobulin and euglobulin lysis times carried out.

out euglobulin lysis times as described in the previous experiment. Calcium was added to all tubes before clotting with thrombin. The E.D.T.A. was used in this experiment to obtain more complete removal of calcium. It can be seen from the results in the previous experiments (Table V) that citrate in concentrations sufficient to prevent clotting does not prevent the formation of anti-activator.

Prolongation of the euglobulin lysis above that of the control, containing inhibitor-free euglobulin alone, was taken as a measure of the anti-activator activity present. The results (Table VI )indicate that

\section{TABLE VI}

EFFECT OF CALCIUM ON DEVELOPMENT OF ANTI-ACTIVATOR ${ }^{1}$ in Vitro

Amount of Added Serum (antiplasmin-free) Euglobulin

0

$0.1 \mathrm{ml} .0 .2 \mathrm{ml} .0 .3 \mathrm{ml} .0 .4 \mathrm{ml} .0 .5 \mathrm{ml}$

Serum incubated

without calcium

Serum incubated

with calcium

130

135

135

135

135

135

${ }^{1}$ Euglobulin lysis times (min.) with the addition of antiplasmin-free euglobulin prepared after incubation of serum in the presence and absence of calcium.

very little anti-activator activity developed in the E.D.T.A. specimen during incubation. Quite considerable anti-activator activity was developed in the serum when calcium was not removed. These results substantially confirm Flute's findings. Calcium thus seems to enhance the development of anti-activator in vitro. This may account for the inhibitory action of calcium on fibrinolysis as measured in plasma.

EFFECT OF CALCIUM ON ANTIPLASMIN ACTIVITY In assessing antiplasmin activity the influence of anti-activator must be borne in mind. Whole blood was incubated in glass at $37^{\circ} \mathrm{C}$. for 30 minutes to permit the complete development of anti-activator activity, the serum then removed and citrate added.

It has already been established that calcium does not further alter anti-activator activity once it has been formed and so the antiplasmin activity of the serum could be assessed directly, in the presence and absence of calcium. Serum $(0.1 \mathrm{ml}$.) was added to $0.4 \mathrm{ml}$. inhibitor-free euglobulin fraction and euglobulin lysis times set up. The results (Table VII) show that the antiplasmin activity of the serum is increased in the presence of calcium.

\section{TABLE VII}

EFFECT OF CALCIUM ON ANTIPLASMIN ACTIVITYY ${ }^{1}$

Test No. Without Calcium (hr.) Calcium Present (hr.)

\begin{tabular}{lrl}
\hline 1 & 13 & 24 \\
2 & 4 & 10 \\
3 & 5 & 11 \\
4 & 7 & 13
\end{tabular}

${ }^{1}$ Euglobulin lysis times (hr.) in the presence and absence of calcium with the addition of $0.1 \mathrm{ml}$. incubated serum.

\section{DISCUSSION}

The inhibitory effect of calcium on lysis in plasma (Sherry et al., 1959), and its accelerating effect on euglobulin clot lysis (Ratnoff, 1952) have been confirmed.

It is well known that metallic ions acting as cofactors can play an important role in enzymatic reactions. It seems that the fibrinolytic system offers no exception: in the absence of inhibitors, the lysis of fibrin proceeds more rapidly when calcium is present. It has not been determined whether calcium accelerates the proteolytic activity of plasmin itself, or influences the activation of plasminogen to plasmin by activator. Ratnoff (1952) believed that activator is affected directly, but could not demonstrate this using streptokinase or chloroform. The elucidation of this problem is made difficult by the fact that any test ultimately depends on the proteolytic activity of plasmin, and thus it is hard to distinguish between activator and plasminogen on the one hand and plasmin on the other.

In the light of the results using the euglobulin fraction, it was thought that the inhibitory effect of calcium in clot lysis could not be due merely to the different type of fibrin formed in the presence of calcium as suggested by Bickford and Sokolow (1961). They pointed out that the sulphydryl-bonded fibrin formed in the presence of calcium is insoluble in urea, and put forward the hypothesis that this sulphydryl-bonded fibrin might also be more resistant to the fibrinolytic enzymes. This difference in solubility of fibrin in urea is dependent on both calcium and the fibrin stabilizing factor (Laki and Lóránd, 1948) and it may be that this factor plays some part in making the clot more resistant to the fibrinolytic enzymes. The failure of calcium to 
inhibit lysis of fibrin clots formed from the euglobulin fraction of plasma points to a more complex mechanism of inhibition.

The hypothesis put forward in this paper is that calcium inhibits fibrinolysis by acting through the inhibitors present in whole blood or plasma.

According to Flute (1960), anti-activator is formed when blood is incubated in contact with glass, and is precipitated with the euglobulin fraction. The inhibition it caused was not enhanced by calcium. However, as reported by Flute (1962), it was found that the formation in vitro of anti-activator requires calcium. This would explain the importance (Fearnley, Balmforth, and Fearnley, 1957) of the rapid dilution of whole blood at $4^{\circ} \mathrm{C}$. in phosphate buffer in the 1 in 10 clot lysis time, so that calcium is removed before anti-activator can be formed.

The antiplasmin activity of plasma was found to be enhanced by calcium and this would contribute to the inhibition by calcium of fibrinolysis in whole blood or plasma. It is not known how calcium influences these inhibitors, or whether its effect is fully explained by this mechanism.

The finding that calcium prevents the spontaneous lysis of unheated fibrin plates prepared from some batches of Armour bovine plasma fraction $I$ is difficult to explain in the light of these results. Fraction I is contaminated by plasminogen and traces of activator; antiplasmins are also present but it is doubtful whether they are sufficient in quantity to account fully for the inhibition of lysis when calcium is added. In such instances it is possible that the effect of calcium on the type of fibrin formed is of predominating importance, due to the lower con

centration of the enzymes and their inhibitors.

It is apparent that the mechanism of inhibition fibrinolysis by calcium in vitro is complex. It partly explained by the effect of calcium on the formation of anti-activator and on antiplasmi $\overline{\bar{p}}$. activity, and is possibly influenced to some extent $b \bar{\phi}$ the type of fibrin formed when calcium is present In whole blood, these inhibitory influences must modify the accelerating effect of calcium observe $\Phi$ when inhibitor-free euglobulin fraction is used.

I would like to thank Dr. J. L. Stafford for suggesting the study, and Dr. M. B. Howell and Miss C. M. Hawkes for help and advice whilst it was being undertaken. The. work was supported by a grant from the St. George's Hospital Research Fund.

\section{REFERENCES}

Astrup, T., and Müllertz, S. (1952). Arch. Biochem., 40, 346. Bickford, A. F. Jr., and Sokolow, M. (1961). Thrombos. Diathe haemorrh. (Stuttg.), 5, 480.

Bidwell, E. (1953). Biochem. J., 55, 497.

Fearnley, G. R., Balmforth, G., and Fearnley, E. (1957). Clin. Scit 16,645 .

- , and Tweed, J. M. (1953). Ibid., 12, 81.

Flute, P. T. (1960). Proc. 7th Congr. europ. Soc. Haemat., Lond., 1959 part II, p. 894.

- (1962). Personal communication.

Kowalski, E., Kopec, M., and Niewiarowski, S. (1959). J. clin. Path 12, 215.

_- Latallo, Z., and Niewiarowski, S. (1956). Sang, 27, 466.

Laki, K., and Lóránd, L. (1948). Science, 108, 280.

Lassen, N. (1953). Acta. physiol. scand., 27, 371.

Medart, W. S. (1958). Proc. Soc. exp. Biol. (N.Y.), 97, 728.

Norman, P. S. (1960). Amer. J. Cardiol., 6, 390.

Ratnoff, O. D. (1952). J. exp. Med., 96, 319.

Sherry, S., Lindemeyer, R. I., Fletcher, A. P., and Alkjaersig, (1959). J. clin. Invest, 38, 810 .

Thomas, W. A. (1958). Personal communication, quoted by Medar 